Boise State University

ScholarWorks

Organizational Performance and Workplace

Learning Faculty Publications and

Department of Organizational Performance and

Presentations

$1-2020$

\title{
Ethical and Responsible Cross-Cultural Interviewing: Theory to \\ Practice Guidance for Human Performance and Workplace \\ Learning Professionals
}

D'Jeane T. Peters

Boise State University

Lisa A. Giacumo

Boise State University

This is the peer reviewed version of the following article:

Peters, D.T. and Giacumo, L.A. (2020). Ethical and Responsible Cross-Cultural Interviewing: Theory to Practice Guidance for Human Performance and Workplace Learning Professionals. Performance Improvement, 59(1), 26-34. which has been published in final form at doi: 10.1002/pfi.21906. This article is published by Wiley on behalf of the International Society for Performance Improvement. It may be used for non-commercial purposes in accordance with Wiley Terms and Conditions for Self-Archiving. 


\title{
Ethical and Responsible Cross-Cultural Interviewing: Theory to Practice Guidance for Human Performance and Workplace Learning Professionals
}

\author{
D'Jeane T. Peters \\ Boise State University \\ Lisa A. Giacumo \\ Boise State University
}

\begin{abstract}
Conducting interviews in a cross-cultural setting is increasingly common for human performance technology (HPT) practitioners and researchers. Planning to conduct interviews in a culture that the practitioner may not be familiar with requires additional methodological and ethical considerations. In this article, we draw from published scholarly works on cross-cultural interviewing practices across disciplines to develop evidence-based recommendations HPT professionals can utilize in their own cross-cultural interview project.
\end{abstract}

In a review of ISPI publications from 1962 until 2010, Huglin (2010) identified globalization as a key research trend in the field of human performance technology (HPT). Globalization requires HPT professionals to be able to work across cultures in a variety of settings. One key research tool for practitioners to use is interviewing, which allows "the HPT analyst or evaluator to acquire in-depth information that is useful" (Pershing, 2006, p. 792). While much as been written about the importance of interviewing in the field of HPT (Duan, 2011; Klein, 2002; Pershing, 2006), and guidelines are given for conducting interviews as an HPT practitioner (Pershing, 2006), there is a dearth of guidance to support cross-cultural interview methodology. Therefore, we have identified a need to support HPT practitioners who are conducting interviews specifically in cross-cultural settings. In this article, we synthesize existing crosscultural interviewing ethical and methodological evidence-based practice guidelines. Further, we apply these guidelines to create practical guidance for professionals working in cross-cultural workplace learning and human performance technology settings.

\section{Interviewing as a Prevalent Tool}

When broken down into its root words, interviewing call be seen as inter (together or connect), view (position), or, in essence, two people "conversing about a theme of common interest" (Kvale, 2007, p. 5). Since the publication of the first field guide to interviewing in 1929, interviewing has been used as a research tool in sociology and anthropology (Platt, 2001). In the past 30 years, it has also become part of education and health science (Kvale, 2007). Additionally, in the field of HPT practitioners, Duan (2011) lists interviewing as one of the five most common data collection methods utilized by practitioners, based on an analysis of 22 published HPT journal articles. In a survey of HPT professionals, Guerra (2003) asked if practitioners currently utilize interviews with stakeholders as a data collection method in their work, and 179 out of 179 respondents stated that they "usually" apply this practice (p. 62). According to Pershing (2006), interviews can help HPT practitioners interpret unclear answers, build rapport, and discuss a wide range of topics that might not arise in a written questionnaire.

\section{Cross-Cultural Research and Data Collection}

Culture is difficult to define. According to Spencer-Oatey (2008), in 1952 Kroeber and Kluckhohn assembled 164 different definitions of culture. Spence-Oatey (2008) chose to utilize the idea that "culture is manifested through different types of regularities and that is associated with culture groups" (p. 15). UNESCO (2017) defines culture as "that complex whole which includes knowledge, beliefs, arts, morals, laws, customs, and any other capabilities and habits acquired by [a human] as a member of society.” Brach’s (1997) definition of culture, while similar, adds clarity for performance improvement professionals by specifying "the epistemology, philosophy, observed traditions, and patterns of action by individuals and human groups” (p. 38). 
This is an author-produced, peer-reviewed version of this article. The final, definitive version of this document can be found online at Performance Improvement, published by Wiley on behalf of the International Society for Performance Improvement. Copyright restrictions may apply. doi: 10.1002/pfi.21906

A research project investigating learning or performance improvement needs, intervention designs, or outcomes, as mediated by culture, can take various approaches. In most cross-cultural work, an emic approach focuses on one culture, while an etic approach focuses on a comparative analysis of two or more cultures (Schaffer \& Riordan, 2003). Either one of these approaches can be taken by human performance improvement practitioners who work across cultures when they formulate and implement data collection plans. Regardless of the approach, collecting data via semi-structured interviews is a common methodological choice.

After analyzing 18 published scholarly research articles on culture and learning in educational communications technology as mentioned in Benson (2018), we found that common methodologies for cross-cultural research includes surveys, individual interviews, focus groups, case studies, and observations, or some combination of these. Unsurprisingly, these comprise many of the same data collection methods used in the field of HPT (Duan, 2011; Pershing, 2006). Through the analysis of semi-structured interview data, practitioners can demonstrate many of the ISPI standards, including take a systematic view (standard 2); work in partnership with clients and stakeholders (standard 4); use data driven analyses to determine cause (standard 6); and evaluate results and impact (standard 10) (ISPI 10 Standards, 2017). The question then becomes, how can performance improvement practitioners best ethically design data collection methods and tools to inform their cross-cultural work?

\section{Specialized Interviewing Methodological Skills}

Ramos-Burkhart (2013) argues for a broad-scale cultural competence to be integrated into all levels of business, including performing "cultural audits to identify where cultural competency efforts need to be focused" as well as providing "community representation and feedback" (p. 3). In her book on cross-cultural qualitative research, Liamputtong (2008) presents the methodological and ethical considerations for cross-cultural interviewing. However, she writes for researchers, and therefore her extensive examples of cross-cultural semi-structured interviewing within the text were all drawn from the research context.

\section{Guidance for Workplace Learning and Performance Improvement Professionals.}

HPT-focused researchers use interviewing in their cross-cultural work (Levacy, 2012; Semali \& Asino, 2014). Levacy (2012) investigated the cultural factors affecting international teamwork in the United States and India, and found a need for additional intercultural competence in the current global business environment. The study utilized qualitative analysis of open-ended questionnaires, and while they do address ethical considerations in their work (including oversight by an institutional review board), no culture-specific interviewing methodology or ethical considerations are explicitly mentioned. Additionally, Semali and Asino (2014) utilized surveys, observations, and follow-up interviews to describe literacy practices among female business owners in Namibia and Tanzania, but do not specify their explicit cultural considerations that emerged during the interview process. While these studies were conducted by experienced practitioners and scholars who are likely already aware of and plan for ethical, practical, and methodological concerns, their work is not intended to guide a novice practitioner through a cross-cultural semistructured interviewing process.

\section{Filling the Cross-Cultural Interview Skills Guidance Gap}

Thus, we have distilled the relevant evidence-based scholarly methodological research to provide accessible, actionable guidance. Workplace learning and performance improvement emerging researchers and practitioners can rely upon our short list of methodological and ethical considerations for cross-cultural interview data collection. Also, we provide practical advice for using semi-structured interviews in the practice of HPT data collection. In short, this work is intended to be evidence-based guidance that combines the 10 ISPI standards (2017) and cross-cultural qualitative research from a variety of disciplines to guide practitioners in their own cross-cultural HPT work.

\section{$\underline{\text { Ethical Considerations }}$}

ISPI standard 4, "work in partnership with clients and stakeholders," is of particular importance when it comes to the ethics of cross-cultural semi-structured interviewing for HPT practitioners (ISPI 10 Standards, 2017). Best practices such as involving the stakeholders and fostering open communication within and between groups are also reflected in the guidance for cross-cultural researchers. Liamputtong (2008) describes that the essence of developing sensitive cross-cultural qualitative research can be captured by the following actions: (a) building trust and rapport with the 
This is an author-produced, peer-reviewed version of this article. The final, definitive version of this document can be found online at Performance Improvement, published by Wiley on behalf of the International Society for Performance Improvement. Copyright restrictions may apply. doi: 10.1002/pfi.21906

interviewees, (b) demonstrating respect for cultural beliefs, (c) understanding that it takes more time for cross-cultural projects to be completed, (d) including members of the population or group of interest, and (e) gathering input on the design of the data collection methods and tools from representative members of the group to be interviewed.

Building Trust. It is important to build trust and rapport because the type of information that participants will share can be dependent upon their trust in the interviewer and larger study. In a survey of 179 HPT professionals, Guerra (2003) found "communicating to those affected by the intervention the associated benefits and risks" (p. 64) is a practice that professionals should always apply to their work. In cross-cultural settings, this can be particularly sensitive due to historical disparities of power between different ethnic groups (Christopher, Watts, McCormick, \& Young, 2008; Merry et al., 2011).

Guidance for Building Trust. Nearly all discussions of interviewing strategies include something about rapport in their guidance. Part of this process is to explain how participants could benefit from their participation, that the information they share will be used to improve their experience in the organization. Rapport is developed when the interviewer includes time to establish trust and respect, as well as respecting the questions the interviewee may ask and answering them authentically (Jennings, 2005).

Demonstrating Respect for Cultural Beliefs. Demonstrating appropriate respect for cultural beliefs requires a level of cultural intelligence on the part of the practitioners. Cultural intelligence is defined by Ang et al. (2007) as a "specific form of intelligence focused on capabilities to grasp, reason, and behave effectively in situations characterized by cultural diversity" (p. 337). For this to be demonstrated, practitioners take on the two-part responsibility of both learning and reflection. Irvine, Roberts, and Bradbury-Jones (2008) suggest that, prior to data collection, researchers spend time in the setting to develop an understanding of the social and cultural norms. Addison and Wittkuhn (2001) suggest that any HPT-focused model that takes culture into consideration should be considered a hypothesis that is adopted for individual companies and cultures. Additionally, HPT ethics standards also call for a practice of reflexivity, or to "recognize the boundaries of their own particular competencies" (Guerra, 2006, p. 1035). Levitt (2015) also recommends that those working internationally "must be sensitive to their own ethnocentric tendencies, by examining their own cultural values and their impacts on self-identity" (p. 18).

Guidance on Respective Cultural Beliefs. In practice, this means collecting both organizational observations and reflective data on the interviewer's experience before, during, and after the data-collection process. To do this, prior to conducting data collection or analysis, a good reflective practice is to note as many assumptions as possible that you have about performance improvement work and your work environment (e.g., access to computers, electricity, transportation, childcare). After collecting the interview data, examine the relationship between your past experiences and the data you collected - think about concepts such as customer service, pace of work, and work-life balance. Do you recognize these reflections as culturally embedded? Discussing your findings with a trusted adviser may also lead to new insights. Hand (2003) gives an excellent example of this type of reflection.

Ethical Cross-Cultural Work Takes More Time. Conducting interviews in the cross-cultural context is no small feat. Nearly all experienced researchers who work in cross-cultural contexts discuss the extensive time that cross-cultural work takes. While practitioners rarely face the same level of scrutiny in their project design methodology and practice as academic scholars, additional time to complete a cross-cultural project should still be built into the plan.

Guidance Comparing Steps Taken During Cross-Cultural Semi-Structured Interviews. Table 1 compares the number of steps in planning and executing three different types of semi-structured interviews: (a) a semi-structured interview conducted for a client in a familiar culture (e.g., an American consulting for a company full of other Americans), (b) an interview conducted where the interviewer and the interviewee do not share the same culture, but do share the same language (e.g., an American interviewer working in India for the first time, where the workforce is Indian and English is the main language spoken in the workplace), and (c) a semi-structured interview across different cultures and languages (e.g., an American interviewer conducting interviews via a translator for a company in Japan, where Japanese is the main language of the workplace). 
This is an author-produced, peer-reviewed version of this article. The final, definitive version of this document can be found online at Performance Improvement, published by Wiley on behalf of the International Society for Performance Improvement. Copyright restrictions may apply. doi: 10.1002/pfi.21906

\section{Table 1}

Comparison of the number of steps in planning and executing three different types of semi-structured interviews

\begin{tabular}{|c|c|c|}
\hline $\begin{array}{l}\text { Semi-Structured Interview Steps } \\
\text { (Whiting, 2008) }\end{array}$ & $\begin{array}{l}\text { Cross-Cultural Semi-Structured } \\
\text { Interview Steps (Liamputtong, 2008; } \\
\text { Whiting, 2008) }\end{array}$ & $\begin{array}{l}\text { Cross-Cultural Semi-Structured } \\
\text { Interview Steps Across Different } \\
\text { Languages (Liamputtong, 2008; Whiting, } \\
\text { 2008) }\end{array}$ \\
\hline Not applicable & $\begin{array}{l}\text { 1. Conduct organizational } \\
\text { observations }\end{array}$ & 1. Conduct organizational observations \\
\hline Not applicable & $\begin{array}{l}\text { 2. Note and reflect on distinctive } \\
\text { cultural norms in the organization }\end{array}$ & $\begin{array}{l}\text { 2. Note and reflect on distinctive cultural } \\
\text { norms in the organization }\end{array}$ \\
\hline Not applicable & $\begin{array}{l}\text { 3. Reflect on your own cultural } \\
\text { experiences and expectations }\end{array}$ & $\begin{array}{l}\text { 3. Reflect on your own cultural experiences } \\
\text { and expectations }\end{array}$ \\
\hline $\begin{array}{l}\text { 1. Consult with the client regarding } \\
\text { the available data }\end{array}$ & $\begin{array}{l}\text { 4. Consult with the client regarding } \\
\text { the available data }\end{array}$ & $\begin{array}{l}\text { 4. Consult with the client regarding the } \\
\text { available data }\end{array}$ \\
\hline $\begin{array}{l}\text { 2. Develop a data collection plan } \\
\text { Develop the interview } \\
\text { questions } \\
\text { Receive approval for the } \\
\text { questions from the client }\end{array}$ & $\begin{array}{l}\text { 5. Develop a data collection plan } \\
\text { Consult with a member(s) } \\
\text { of the target group on } \\
\text { culturally sensitive interview } \\
\text { practices } \\
\text { Develop the interview } \\
\text { questions } \\
\text { Receive approval for the } \\
\text { questions from the client }\end{array}$ & $\begin{array}{l}\text { 5. Develop a data collection plan } \\
\text { Consult with a member(s) of the } \\
\text { target group on culturally sensitive } \\
\text { interview practices } \\
\text { Develop the interview questions } \\
\text { Receive approval for the } \\
\text { questions from the client }\end{array}$ \\
\hline 3. Pilot interview questions & 6. Pilot interview questions & 6. Pilot interview questions \\
\hline Not applicable & Not applicable & $\begin{array}{l}\text { 7. Translate interview questions, if needed. } \\
\text { • Get an interpreter, if needed }\end{array}$ \\
\hline Not applicable & Not applicable & $\begin{array}{l}\text { 8. Pilot translated interview questions with } \\
\text { a few individuals who are not part of the } \\
\text { target audience but have similar prior } \\
\text { knowledge }\end{array}$ \\
\hline
\end{tabular}


This is an author-produced, peer-reviewed version of this article. The final, definitive version of this document can be found online at Performance Improvement, published by Wiley on behalf of the International Society for Performance Improvement. Copyright restrictions may apply. doi: 10.1002/pfi.21906

\begin{tabular}{|c|c|c|}
\hline $\begin{array}{l}\text { 4. Identify your interviewees } \\
\text { Receive their permission } \\
\text { Inform them of: } \\
\text { - } \quad \text { Purpose of the interview } \\
\text { - } \text { Clarification of the topic } \\
\text { Approximate length of } \\
\text { the interview } \\
\text { Assurance of } \\
\text { confidentiality } \\
\text { Purpose of the recorder } \\
\text { Assurance that they may } \\
\text { seek clarification } \\
\text { Assurance that they may } \\
\text { decline to answer questions } \\
\text { Assurance that they may } \\
\text { ask questions of the } \\
\text { interviewer }\end{array}$ & $\begin{array}{l}\text { 7. Identify your interviewees } \\
\text { - } \quad \text { Receive their permission } \\
\text { to interview them } \\
\text { Inform them of: } \\
\text { - } \quad \text { Purpose of the interview } \\
\text { - } \text { Clarification of the topic } \\
\text { - } \text { Approximate length of the } \\
\text { interview } \\
\text { - } \text { Assurance of } \\
\text { - } \text { Purpose of the recorder } \\
\text { Assurance that they may } \\
\text { seek clarification } \\
\text { - Assurance that they may } \\
\text { decline to answer questions } \\
\text { Assurance that they may } \\
\text { ask questions of the } \\
\text { interviewer }\end{array}$ & $\begin{array}{l}\text { 9. Identify your interviewees } \\
\text { Receive their permission to } \\
\text { interview them } \\
\text { Inform them of: } \\
\text { - } \quad \text { Purpose of the interview } \\
\text { - } \quad \text { Forification of the topic } \\
\text { - Approximate length of the } \\
\text { - } \quad \text { Assurance of confidentiality } \\
\text { - Assurance that they may seek } \\
\text { - } \quad \text { Alarification } \\
\text { - } \text { Assurance that they may decline } \\
\text { Assurance that they may ask } \\
\text { questions of the interviewer }\end{array}$ \\
\hline $\begin{array}{l}\text { 5. Conduct the interview } \\
\text { Ideally in a quiet, private } \\
\text { room }\end{array}$ & $\begin{array}{l}\text { 8. Conduct the interview } \\
\text { Ideally in a quiet, private } \\
\text { room }\end{array}$ & $\begin{array}{l}\text { 10. Conduct the interview with the help of } \\
\text { an interpreter } \\
\text { Ideally in a quiet, private room }\end{array}$ \\
\hline Not applicable & $\begin{array}{l}\text { 9. Note and reflect on your own } \\
\text { cultural norms and their influence on } \\
\text { the interview process }\end{array}$ & $\begin{array}{l}11 . \text { Note and reflect on your own cultural } \\
\text { norms and their influence on the interview } \\
\text { process }\end{array}$ \\
\hline Not applicable & Not applicable & 12. Translate interview responses, if needed \\
\hline 6. Transcribe the interview data & 10. Transcribe the interview data & 13. Transcribe the interview data \\
\hline 7. Code and categorize the data & 11. Code and categorize the data & 14. Code and categorize the data \\
\hline Not applicable & $\begin{array}{l}\text { 12. Note and reflect on your own } \\
\text { cultural norms and their influence on } \\
\text { the interview process }\end{array}$ & $\begin{array}{l}\text { 15. Note and reflect on your own cultural } \\
\text { norms and their influence on the interview } \\
\text { process }\end{array}$ \\
\hline 8. Interpret results & 13. Interpret results & 16. Interpret results \\
\hline Not applicable & $\begin{array}{l}\text { 14. Note and reflect on your own } \\
\text { cultural norms and their influence on } \\
\text { the interview process }\end{array}$ & $\begin{array}{l}\text { 17. Note and reflect on your own cultural } \\
\text { norms and their influence on the interview } \\
\text { process }\end{array}$ \\
\hline Not applicable & Not applicable & 18. Translate the results \\
\hline
\end{tabular}

Taking a Participatory Approach. Finally, both HPT practitioners and cross-cultural researchers encourage two levels of participation from the subjects of the work. The first level, as suggested by Liamputtong (2008), is that the members of the population of interest should be included in the study, informed of their basic rights as participants, and shown how the study will be used (Merry et al., 2011; Qu \& Dumay, 2011). The second, and equally critical level, is to gather input on the data collection design prior to data collection. This aligns with Young's (2008) culture-based model of instructional design, which calls for participation at all levels of typical educational technology projects and processes. We would further extend this recommendation to any needs assessment, evaluation, or other performance improvement project process. 
This is an author-produced, peer-reviewed version of this article. The final, definitive version of this document can be found online at Performance Improvement, published by Wiley on behalf of the International Society for Performance Improvement. Copyright restrictions may apply. doi: 10.1002/pfi.21906

Guidance for a Participatory Approach. By approaching the interview process as a collaborative partnership, both the client and the participants benefit from the exchange. In other words, this means workplace learning and performance improvement professionals would give the same consideration to a stakeholder of a different culture, as they would when following ISPI standard 4, work in partnership with clients and stakeholders (ISPI 10 Standards, 2017).

\section{Methods to Use in Cross-Culture Interviews}

Liamputtong (2008) also describes methodological considerations when conducting cross-cultural research. These include language issues, access to participants, and issues surrounding informed consent. While these are not the only methodological considerations that should be considered when designing a semi-structured interview, there are specific challenges in these areas in a cross-cultural setting.

Language, Translation, and Nonverbal Cues. The language that will be used in cross-cultural semi-structured interviews is an important methodological consideration. In the case of using translators, Liamputtong (2008) suggests that working with fewer interpreters over longer periods of time can help the interpreters develop an understanding of the research aims and questions. Ultimately, HPT practitioners and researchers should be aware that translators produce text from their own perspective (Liamputtong, 2008), and that rendering the translator invisible to the data collection process should be avoided (Squires, 2009).

Guidance for Language and Translation. To make the interview data collection valid, careful attention must be paid to question prompt design and conversations in second languages. Translated question prompts can lose their meaning, which means practitioners are at a higher risk of collecting data that will not provide insight on workplace systems, functions, processes, or environments. Cross-checking the translated questions with the help of a translator that is proficient in both the linguistic mechanics and cultural implications of the question can lead to better data collection.

Overall, conversations with individuals who are second-language speakers are also more complex for interviewers and take much more time (Koulouriotis, 2011). While there is some debate about when to use or not use translators for second-language speakers (Koulouriotis, 2011), it should be noted that assuming a second- or third-language speaker requires translation could show a lack of trust in the participant by the interviewer. Overall, we recommend you ask the participant what language he or she prefers to use during the interview. Regardless, interviewers should plan their question wording carefully, avoid colloquialisms, and allow participants more time to answer questions in their second or third language.

To improve the quality of the data gathered during an interview, Hopf (2004) makes the suggestion for all novice interviewers to avoid common errors, including a tendency to dominate communication, asking overly complex or multiple questions, and a lack of patience in listening. While these are good practices to be aware of overall, they are particularly important in the cross-cultural context. If possible, an interviewer should practice his or her skills with a mentor who is not involved with the interviewer's research (Whiting, 2008).

Of equal importance to verbal communication is nonverbal communication practices that may occur during the interview. Cultural display rules as discussed in Hwang and Matsumoto (2013) are the norms that "govern the management and modification of emotional displays depending on social circumstances" (p. 119). Since these are not universal across cultures, researching them prior to embarking on a cross-cultural interview project will provide additional context during the interview process. Additionally, nonverbal behavioral norms should be included as part of the observations conducted prior to, and after, the interview. This will help the interviewer to develop rapport and trust with participants.

Sampling. Accessing participants is another challenge to cross-cultural interviewing. You will need to consider intentional representation of different subpopulations and think carefully about the impact relationship building can have on your sampling. Qu and Dumay (2011) also establish that gaining access to participants is a challenge that can be overcome by developing a strong rapport with the interviewees. Merry et al. (2011) credits access to key informants previously inaccessible as a result of snowball sampling. In addition to snowball sampling, Liamputtong (2008) recommends using a wide network of participants to overcome sampling challenges. 
This is an author-produced, peer-reviewed version of this article. The final, definitive version of this document can be found online at Performance Improvement, published by Wiley on behalf of the International Society for Performance Improvement. Copyright restrictions may apply. doi: 10.1002/pfi.21906

Guidance for Sampling Participants in a Cross-Cultural Setting. In practice, snowball sampling means to gather a sample of participants, and then have each of those participants refer a number of additional participants, and so on, until an adequate sample size is reached. Goodman (1961) describes a mathematical proof to justify the representative efficacy of snowball sampling. This approach works best if interviewees trust their interviewer, since they are more likely to refer their friends or colleagues. Particularly in large organizations, an interviewee's job title does not always align perfectly with his or her duties. In these situations, sampling through the snowball method may be advisable to gain access to the appropriate participants. However, other sampling methods such as random sampling or convenience sampling may also be appropriate, depending on the project design, organizational context, number of potential participants that fit the selection criteria, and level of sponsorship.

Informed Consent. Obtaining informed consent for interviews is not limited to scholarly academic research practices that are overseen by institutions or peer-reviewed journals. Practitioners outside of academia as well should "respect the right of individuals to privacy, confidentiality, self-determination, and autonomy, mindful that legal and other obligations may lead to inconsistency and conflict with the exercise of such rights” (Guerra, 2006 p. 1035). Additionally, obtaining informed consent may be a challenge working with some groups, which can be overcome by obtaining verbal consent (Liamputtong, 2008). However, true voluntary decision making by the interviewees can be impacted by barriers such as poverty, illiteracy, and trust in local authority figures, and therefore should be carefully considered on a case-by-case basis (Miller \& Boulton, 2007; Tekola et al., 2009).

Guidance for Obtaining Informed Consent. Within any organization, there is an inherent power structure that should not be ignored, and therefore we recommend that obtaining informed consent is carefully planned. Thinking about the project plan to obtain informed consent, and any potential barriers the practitioner may encounter, is another key reflective practice. In addition to planning for how to explain the purpose of the interview; any potential benefits to the participants; your plans to maintain participants' confidentiality; and how you would secure any personally identifiable information, share aggregated results, and dispose of the raw data, there may be additional context-specific hurdles.

For example, it is possible that both the interviewing process and the ethics surrounding the interview may mean something different to the interviewer and the interviewee (Koulouriotis, 2011). In some instances, to achieve true consent and full participation, you may need to work with a local collaborator to collect and analyze data. Also, the power dynamics of the exchange should be taken on as part of the reflective practice of interviewing. Involve a representative colleague collaborator from the cultural group to help you become familiar with the concerns of the potential interview participants and help explain how you would address these concerns in accessible terms.

\section{Conclusion}

To summarize, workplace learning and HPT practitioners and researchers alike should consider how to plan for the following ethical and methodological challenges during a cross-cultural interview collection project: building trust with interviewees, demonstrating respect for cultural beliefs, incorporating with cross-cultural experts for a participatory approach, considering the logistics of language and translation, sampling participants carefully, and gaining adequate informed consent. Overall, professionals who conduct this cross-cultural work will often require more time to complete project deliverables than a comparable scope of work in one's native culture. Planning for additional project resources should be a first step in any cross-cultural project. These resources may include but are not limited to additional project time for organizational observations, funding for translation services, guidance from cross-cultural experts, and consideration for the challenges or barriers that may exist to obtaining informed consent.

Additionally, workplace learning or HPT practitioners doing cross-cultural work should create a plan for incorporating reflective practice into their project. Reflexive practice includes taking the time to carefully deconstruct your own embedded assumptions based on cultural norms and past experiences, and thinking critically about how they could disrupt or influence your collaborators, participants, and cross-cultural project outcomes. Doing this is particularly important when gathering organizational observations, prior to and after conducting interviews.

Finally, we believe that more research and focus should be placed on the work professionals do to plan for ethical and responsible cross-cultural scholarly research and organizational performance improvement work. When sharing work in academic or scholarly publications and conference presentations or workshops, these specialized approaches and considerations should be discussed. As the world becomes smaller and more interconnected, we have a responsibility for our emerging practitioners and scholars to be equipped with the preparation and expectations to perform 
This is an author-produced, peer-reviewed version of this article. The final, definitive version of this document can be found online at Performance Improvement, published by Wiley on behalf of the International Society for Performance Improvement. Copyright restrictions may apply. doi: 10.1002/pfi.21906

responsibly and ethically. Explicit guidance to this end will help our community learn to partner and build stronger relationships with our global colleagues and better connect with potential mentors who can deepen our understanding of the complexities in our practice and the world around us.

\section{References}

Addison, R. M., \& Wittkuhn, K. D. (2001). HPT: The culture factor. Performance Improvement, 40(3), 14-19.

Ang, S., Van Dyne, L., Koh, C., Ng, K. Y., Templer, K. J., Tay, C., \& Chandrasekar, N. A. (2007). Cultural intelligence: Its measurement and effects on cultural judgment and decision making, cultural adaptation and task performance. Management and Organization Review, 3(3), 335-371.

Benson, A. D. (2018). A Typology for conducting research in culture, learning and technology. TechTrends, 62(4), 329-335.

Branch, R. M. (1997, March-April). Educational technology frameworks that facilitate culturally pluralistic instruction. Educational Technology, 37(2), 38-40.

Christopher, S., Watts, V., McCormick, A. K. H. G., \& Young, S. (2008). Building and maintaining trust in a community-based participatory research partnership. American Journal of Public Health, 98(8), 13981406.

Duan, M. (2011). Application of data collection techniques by human performance technology practitioners. Performance Improvement Quarterly, 24(3), 77-100.

Goodman, L. A. (1961). Snowball sampling. The Annals of Mathematical Statistics, 32(1), 148-170.

Guerra, I. J. (2003). Key competencies required of performance improvement professionals. Performance Improvement Quarterly, 16(1), 55-72.

Guerra, I. J. (2006). Standards and ethics in human performance technology. In J. L. Pershing (Ed.), Handbook of human performance technology (pp. 1024-1046). San Francisco, CA: Pfeiffer.

Hand, H. (2003). The mentor's tale: A reflexive account of semi-structured interviews. Nurse Researcher, 10(3), 1527.

Hopf, C. (2004). Qualitative interviews: An overview. In U. Flick, E. von Kardorff, \& I. Steinke (Eds.), A companion to qualitative research (pp. 203-207). Thousand Oaks, CA: Sage Publications.

Huglin, L. M. (2010). Research themes in HPT: A content review of the ISPI journals. Performance Improvement, 49(4), 9.

Hwang, H. C., \& Matsumoto, D. (2013). Nonverbal behaviors and cross-cultural communication in the New Era. In F. Sharifian \& M. Jamarani (Eds.), Language and intercultural communication in the new era (pp. 116137). Abingdon-on-Thames, UK: Routledge.

Irvine, F., Roberts, G., \& Bradbury-Jones, C. (2008). The researcher as insider versus the researcher as outside: Enhancing rigour through language and cultural sensitivity. In P. Liamputtong (Ed.), Doing cross-cultural research (pp. 35-48). New York, NY: Springer.

ISPI 10 Standards. (2017). Retrieved from https://owl.purdue.edu/owl/research_and_citation/apa_style/apa_formatting_and_style_guide/reference_list _electronic_sources.html

Jennings, G. R. (2005). Interviewing: A focus on qualitative techniques. In B. W. Ritchie, P. W. Burns, \& C. Palmer (Eds.), Tourism research methods (pp. 99-118). Cambridge, MA: CABI Publishing.

Klein, J. D. (2002). Empirical research on performance improvement. Performance Improvement Quarterly, 15(1), 99-110.

Koulouriotis, J. (2011). Ethical considerations in conducting research with non-native speakers of English. TESL Canada Journal, 28, 1.

Kvale, S. (2007). Conducting an interview. In S. Kvale (Ed.), Doing interviews (pp. 51-66). Thousand Oaks, CA: Sage Publications.

Levacy, W. (2012). Asian Indian perspectives: Cultural competencies needed to work effectively with Americans on intercultural project teams (Doctoral dissertation). Capella University.

Levitt, S. R. (2015). Cultural factors affecting international teamwork dynamics. International Journal of Knowledge, Culture \& Change in Organizations: Annual Review, 13.

Liamputtong, P. (2008). Doing research in a cross-cultural context: Methodological and ethical challenges. In P. Liamputtong (Ed.), Doing cross-cultural research (pp. 3-20). New York, NY: Springer.

Merry, L., Clausen, C., Gagnon, A. J., Carnevale, F., Jeannotte, J., Saucier, J. F., \& Oxman-Martinez, J. (2011). Improving qualitative interviews with newly arrived migrant women. Qualitative Health Research, 21(7), 976-986. 
This is an author-produced, peer-reviewed version of this article. The final, definitive version of this document can be found online at Performance Improvement, published by Wiley on behalf of the International Society for Performance Improvement. Copyright restrictions may apply. doi: 10.1002/pfi.21906

Miller, T., \& Boulton, M. (2007). Changing constructions of informed consent: Qualitative research and complex social worlds. Social Science \& Medicine, 65(11), 2199-2211.

Pershing, J. L. (2006). Interviewing to analyze and evaluate human performance technology. In J. L. Pershing (Ed.), Handbook of human performance technology. San Francisco, CA: Pfeiffer.

Platt, J. (2001). The history of the interview. In J. F. Gubrium \& J. A. Holstein (Eds.), Handbook of interview research (pp. 33-54). Thousand Oaks, CA: Sage Publications.

Qu, S. Q., \& Dumay, J. (2011). The qualitative research interview. Qualitative Research in Accounting \& Management, 8(3), 238-264.

Ramos-Burkhart, M. (2013). Do you see what I see: How a lack of cultural competency may be affecting your bottom line. Jury Expert, 25, 20.

Schaffer, B. S., \& Riordan, C. M. (2003). A review of cross-cultural methodologies for organizational research: A best-practices approach. Organizational Research Methods, 6(2), 169-215.

Semali, L. M., \& Asino, T. I. (2014). Postliteracy in the digital age: The use of mobile phones to support literacy practices in Namibia and Tanzania. Prospects, 44(1), 81-97.

Spencer-Oatey, H. (Ed.). (2008). Culturally speaking (second edition): Culture, communication and politeness theory. London, UK: Bloomsbury Publishing.

Squires, A. (2009). Methodological challenges in cross-language qualitative research: A research review. International Journal of Nursing Studies, 46(2), 277-287.

Tekola, F., Bull, S. J., Farsides, B., Newport, M. J., Adeyemo, A., Rotimi, C. N., \& Davey, G. (2009). Tailoring consent to context: Designing an appropriate consent process for a biomedical study in a low income setting. PLoS Neglected Tropical Diseases, 3(7), e482.

UNESCO. (2017). Cultural diversity. Retrieved from http://www.unesco.org/new/en/social-and-humansciences/themes/international-migration/glossary/cultural-diversity

Whiting, L. S. (2008). Semi-structured interviews: Guidance for novice researchers. Nursing Standard, 22(23), 3540

Young, P. A. (2008). The culture based model: Constructing a model of culture. Journal of Educational Technology \& Society, 11(2), 107-118. 